\title{
Predictors of Medication Adherence Postdischarge: The Impact of Patient Age, Insurance Status, and Prior Adherence
}

\author{
Marya J. Cohen, MD, MPH${ }^{1 *}$, Shimon Shaykevich, $\mathrm{MS}^{2}$, Courtney Cawthon, $\mathrm{MPH}^{3}$, Sunil Kripalani, MD, MSc ${ }^{3,4}$, \\ Michael K. Paasche-Orlow, MD, MA, MPH${ }^{5}$, Jeffrey L. Schnipper, MD, MPH ${ }^{6}$
}

\begin{abstract}
'Division of General Medicine, Massachusetts General Hospital, Harvard Medical School, Boston, Massachusetts; ${ }^{2}$ Division of General Medicine, Brigham and Women's Hospital, Boston, Massachusetts; '3nstitute for Medicine and Public Health, Vanderbilt Center for Health Services Research, Nashville, Tennessee; "4Section of Hospital Medicine, Division of General Internal Medicine and Public Health, Department of Medicine, Vanderbilt University, Nashville, Tennessee; ${ }^{5}$ Section of General Internal Medicine, Boston Medical Center, Boston University School of Medicine, Boston, Massachusetts; 'BWH Hospitalist Service and Division of General Medicine, Brigham and Women's Hospital, Harvard Medical School, Boston, Massachusetts.
\end{abstract}

BACKGROUND: Optimizing postdischarge medication adherence is a target for avoiding adverse events. Nevertheless, few studies have focused on predictors of postdischarge medication adherence.

METHODS: The Pharmacist Intervention for Low Literacy in Cardiovascular Disease (PILL-CVD) study used counseling and follow-up to improve postdischarge medication safety. In this secondary data analysis, we analyzed predictors of self-reported medication adherence after discharge. Based on an interview at 30-days postdischarge, an adherence score was calculated as the mean adherence in the previous week of all regularly scheduled medications. Multivariable linear regression was used to determine the independent predictors of postdischarge adherence.

RESULTS: The mean age of the 646 included patients was 61.2 years, and they were prescribed an average of 8 daily medications. The mean postdischarge adherence score was $95 \%$ (standard deviation [SD] $=10.2 \%$ ). For every $10-$ year increase in age, there was a $1 \%$ absolute increase in postdischarge adherence (95\% confidence interval [Cl] $0.4 \%$ to $2.0 \%$ ). Compared to patients with private insurance, patients with Medicaid were $4.5 \%$ less adherent $(95 \% \mathrm{Cl}-7.6 \%$ to $-1.4 \%)$. For every 1 -point increase in baseline medication adherence score, as measured by the 4-item Morisky score, there was a $1.6 \%$ absolute increase in postdischarge medication adherence $(95 \% \mathrm{Cl} 0.8 \%$ to $2.4 \%)$. Surprisingly, health literacy was not an independent predictor of postdischarge adherence.

CONCLUSIONS: In patients hospitalized for cardiovascular disease, predictors of lower medication adherence postdischarge included younger age, Medicaid insurance, and baseline nonadherence. These factors can help predict patients who may benefit from further interventions. Journal of Hospital Medicine 2012;7:470-475. (c) 2012 Society of Hospital Medicine
In the outpatient setting, medication adherence (defined as percentage of prescribed medication doses taken by a patient during a specific time period) ranges between $40 \%$ and $80 \%$ for chronic conditions. ${ }^{1}$ During acute care hospitalization, changes are often made to patients' medication regimens, which can be confusing and contribute to nonadherence, medication errors, and harmful adverse events. ${ }^{2}$ Indeed, it is estimated that almost half of patients encounter a medication error after discharge, and approximately $12 \%-17 \%$ experience an adverse drug event after returning home. ${ }^{3-6}$ It is likely that some of these adverse events may be the result of medication nonadherence. ${ }^{7}$ Improved patient-provider communi-

*Address for correspondence and reprint requests: Marya J. Cohen, MD, MPH, General Medicine Unit, Massachusetts General Hospital, 50 Staniford St, 9th Floor, Boston, MA 02114; Telephone: 617-889-8580; Fax: 617-889-8579; E-mail: mjcohen@partners.org

Additional Supporting Information may be found in the online version of this article.

Received: October 17, 2011; Revised: March 4, 2012; Accepted: March 12,2012

2012 Society of Hospital Medicine DOI 10.1002/jhm.1940

Published online in Wiley Online Library (Wileyonlinelibrary.com). cation, systems to reconcile prehospitalization and posthospitalization medications, as well as development of mechanisms to enhance adherence, may prevent many of these errors and have become new targets for quality improvement. ${ }^{4,8}$ Although postdischarge medication adherence is a crucial target for avoiding adverse events and rehospitalization, few studies have focused on understanding its incidence and predictors, in particular, patient demographic factors such as age and insurance status. ${ }^{9-11}$

In addition, few studies have looked at general and posthospital adherence in a population where health literacy is measured, an important area because medication changes during hospitalization may be particularly confusing for patients with low health literacy. ${ }^{11,12}$ Health literacy is defined as "the degree to which an individual has the capacity to obtain, process, and understand basic health information and services needed to make appropriate health decisions."13 Prior outpatient research shows that low health literacy is associated with poor patient understanding of the medication regimen and instructions for medication use, which may contribute to postdischarge medication nonadherence. ${ }^{14,15}$ Understanding the factors associated with postdischarge medication 
adherence could help refine interventions that are oriented toward improving transitions in care, patient safety, and reducing unnecessary rehospitalization.

We report here on factors associated with postdischarge medication adherence using data from the Pharmacist Intervention for Low Literacy in Cardiovascular Disease (PILL-CVD) study. ${ }^{16}$

\section{METHODS}

\section{Study and Participants}

PILL-CVD was a federally funded, 2-site randomized controlled trial using pharmacist-assisted medication reconciliation, inpatient pharmacist counseling, lowliteracy adherence aids, and telephone follow-up that aimed to decrease rates of serious medication errors after hospital discharge. ${ }^{16}$ The study targeted patients with cardiovascular disease (hospitalized on cardiology or general medical or geriatric services for acute coronary syndromes [ACS] or acute decompensated heart failure [ADHF]) at 2 large academic hospitals, Brigham and Women's Hospital (BWH) and Vanderbilt University Hospital (VUH).

Subjects were eligible for enrollment if they met criteria for ACS or ADHF, were likely to be discharged to home as determined by the primary medical team at the time of study enrollment, and took primary responsibility for administering their medications prior to admission (caregivers could be involved in medication management after discharge). Exclusion criteria included severe visual or hearing impairment, inability to communicate in English or Spanish, active psychiatric illness, dementia, delirium, illness too severe to participate, lack of a home phone number, being in police custody, or participation in another intensive medication adherence program (eg, due to renal transplant).

Out of 6416 patients originally screened for possible enrollment, 862 were randomly assigned to receive usual care or usual care plus the intervention, and 851 remained in the study. ${ }^{16}$ Both the main study and this secondary data analysis were approved by the Institutional Review Boards of each site.

\section{Baseline Measures}

Following informed consent and study enrollment, a variety of baseline data were collected on study participants from medical records and patient interview, including primary language, demographic information (age, race, insurance status, income, and education level), cognition (through administration of the 0-5-point MiniCog scale), ${ }^{17}$ and level of health literacy (through use of the $0-$ 36-point short form of the Test of Functional Health Literacy in Adults [s-TOFHLA] scale). ${ }^{18}$ Baseline information was also collected on medication use, including number of preadmission medications, measurement of selfreported adherence prior to admission (using the Morisky scale, a validated 0-4-point questionnaire shown to correlate with disease control and indicative of general patterns of adherence), ${ }^{19}$ and a medication understanding score, adapted from other instruments, which quantifies understanding of the indication, dose, and frequency of up to 5 randomly selected preadmission medications on a $0-3-$ point scale. ${ }^{16,20,21}$

\section{Outcome Measures}

Outcomes were collected 30 days postdischarge through a structured questionnaire, administered by telephone. Only patients who completed this call are included in the present analysis. Postdischarge medication adherence was assessed by asking patients to report the number of days out of the previous week they had taken each medication from their postdischarge regimen exactly as prescribed. ${ }^{22}$ A score was calculated for each medication as the proportion of adherent days (eg, if a patient reported missing 2 days of a medication in the previous week, then adherence would be $5 / 7$ or $71 \%$ ). A global postdischarge adherence score was then derived for each patient by averaging the adherence score for all regularly scheduled medications. This quantitative measure focused on adherence to medications patients knew they should be taking and did not measure medication discrepancies (sometimes termed "unintentional nonadherence").

\section{Analysis}

Patient characteristics were summarized and reported using simple descriptive statistics. Candidate predictors of postdischarge medication adherence were chosen a priori from patient characteristics assessed during hospital admission. These included patient age, gender, race, ethnicity, marital status, insurance, years of education, presence of primary care physician (PCP), study site, number of preadmission medications, medication understanding, baseline adherence, cognition, and health literacy. Unadjusted results were calculated using univariable linear regression, with each patient's adherence score as the dependent variable and each predictor as the independent variable. Adjusted results were then derived using multivariable linear regression with all the candidate predictors in the model.

Lastly, because of missing data for some predictors, in particular baseline adherence and medication understanding, multiple imputation techniques were used to impute missing data and increase statistical power. ${ }^{23}$ We used the Markov Chain Monte Carlo (MCMC) method for multiple imputation, which generally assumes that the data came from a normal distribution and that the missing data are missing at random. Because of the essentially normal distribution of the data, and because the amount of missing data was so small $(<1 \%$ for almost all variables, $5 \%$ for baseline adherence, and $8 \%$ for medication understanding), we expected little bias and present the complete case analysis, which maximized statistical power.

Two-sided $P$ values $<0.05$ were considered significant, and SAS version 9.2 (Cary, NC) was used for all analyses. 


\begin{tabular}{|c|c|c|c|c|}
\hline Characteristic & $\begin{array}{l}\text { Total N, 30-Day } \\
\text { Respondents }\end{array}$ & Value & $\begin{array}{l}\text { Total } \mathrm{N}, \\
\text { Nonrespondents }\end{array}$ & Value \\
\hline Age, mean in yr (SD) & 646 & $61.2(13.5)$ & 45 & $55.4(14.3)$ \\
\hline Gender, N (percentage) & 646 & & 45 & \\
\hline Female & & $272(42.1)$ & & $18(40.0)$ \\
\hline Male & & $374(57.9)$ & & $27(60.0)$ \\
\hline Race, N (percentage) & 643 & & 45 & \\
\hline White & & $511(79.5)$ & & $32(71.1)$ \\
\hline Black & & 104 (16.2) & & $11(24.4)$ \\
\hline Other & & $28(4.4)$ & & $2(4.4)$ \\
\hline Ethnicity, N (percentage) & 639 & & 45 & \\
\hline Hispanic & & $24(3.8)$ & & $1(2.2)$ \\
\hline Not Hispanic & & $615(96.2)$ & & $44(97.8)$ \\
\hline Marital status, N (percentage) & 646 & & 45 & \\
\hline Married/cohabitate & & $382(59.1)$ & & $20(44.4)$ \\
\hline Separated/divorced & & $118(18.3)$ & & $11(24.4)$ \\
\hline Widowed & & $81(12.5)$ & & $5(11.1)$ \\
\hline Never married & & $65(10.1)$ & & $9(2.0)$ \\
\hline Insurance type, N (percentage) & 646 & & 45 & \\
\hline Medicaid & & $53(8.2)$ & & $5(11.1)$ \\
\hline Medicare & & $270(41.8)$ & & $13(28.9)$ \\
\hline Private & & $289(44.7)$ & & $19(42.2)$ \\
\hline Self-pay & & $34(5.3)$ & & $8(17.8)$ \\
\hline Years of education, mean in yr (SD) & 643 & $14.0(3.1)$ & 45 & $13.3(2.7)$ \\
\hline Presence of PCP prior to admission, N (percentage) & 646 & & 45 & \\
\hline Yes & & $596(92.3)$ & & $38(84.4)$ \\
\hline No & & $50(7.74)$ & & $7(15.6)$ \\
\hline Site, N (percentage) & 646 & & 45 & \\
\hline Site 1 & & $358(55.4)$ & & $8(17.8)$ \\
\hline Site 2 & & $288(44.6)$ & & $37(82.2)$ \\
\hline №. of preadmission medications, mean no. (SD) & 641 & $7.8(4.8)$ & 45 & $7.7(5.4)$ \\
\hline Medication understanding score, mean (SD)* & 597 & $2.4(0.5)$ & 40 & $2.2(0.62)$ \\
\hline Health literacy (s-TOFHLA) score, mean (SD)† & 642 & $29.1(8.9)$ & 45 & $26.0(12.0)$ \\
\hline Baseline adherence (SD)‡ & 613 & $2.7(1.1)$ & 45 & $2.4(1.2)$ \\
\hline MiniCog score, N (percentage)S & 646 & & 45 & \\
\hline Demented & & $63(9.8)$ & & $5(11.1)$ \\
\hline Not demented & & $583(90.2)$ & & $40(88.9)$ \\
\hline
\end{tabular}

\section{RESULTS}

Table 1 shows descriptive baseline patient characteristics of study sample (responders) as well as nonresponders at 30 days. For the responders, the mean age of the 646 patients was 61.2 years, $94.7 \%$ were insured, and $19.3 \%$ had inadequate or marginal health literacy. Patients were prescribed an average of 8 preadmission medications. Most patients (92.3\%) had a regular PCP prior to admission. Nonresponders had nonsignificant trends towards having lower health literacy, medication understanding, and baseline medication adherence.

The average postdischarge adherence score was $95 \%$ (standard deviation $[\mathrm{SD}]=10.2 \%$ ), and less than $10 \%$ of patients had an adherence score of less than $85 \%$; overall the distribution was left-skewed. Table 2 illustrates crude and adjusted parameter estimates for variables in the model. Table 3 shows significant findings in the fully adjusted model, which used multiple imputation techniques to account for missing data.
Intervention arm was of borderline statistical significance in predicting postdischarge adherence $(P=$ 0.052), and so was removed from the final model. Study site, age, insurance, and baseline adherence were the only significant independent predictors of postdischarge adherence in the fully adjusted model (Table 3). For example, for every 10 -year increase in age, patients had, on average, an adjusted $1 \%$ absolute increase in their adherence score $(95 \%$ confidence interval $[\mathrm{CI}] \quad 0.4 \%$ to $2.0 \%)$. For every 1-point increase in baseline medication adherence (based on the Morisky scale), there was a $1.6 \%$ absolute increase in medication adherence $(95 \%$ CI $0.8 \%$ to $2.4 \%$ ). In unadjusted analyses, patients with Medicaid were less adherent with medications after discharge than were patients with private insurance. This difference became nonsignificant in adjusted analyses, but when analyses were repeated using multiple imputation techniques, the results again became statistically significant-Medicaid insurance was associated with a $4.5 \%$ absolute decrease in postdischarge adherence 


\begin{tabular}{|c|c|c|c|c|}
\hline Predictor & $\begin{array}{l}\text { Crude Parameter Estimate } \\
\text { (Beta) With 95\% Confidence Intervals }\end{array}$ & $P$ Value & $\begin{array}{l}\text { Adjusted Parameter Estimate (Beta) } \\
\text { With 95\% Confidence Intervals }\end{array}$ & $P$ Value \\
\hline Age per $10 \mathrm{yr}$ & $0.010(0.007,0.020)$ & $<0.0001$ & $0.010(0.002,0.020)$ & 0.018 \\
\hline Male gender & $0.012(-0.004,0.028)$ & 0.137 & $0.003(-0.014,0.020)$ & 0.727 \\
\hline \multicolumn{5}{|l|}{ Race/ethnicity } \\
\hline White & $0.011(-0.009,0.031)$ & 0.266 & Ref & Ref \\
\hline Black & $-0.017(-0.038,0.005)$ & 0.13 & $0.006(-0.017,0.030)$ & 0.598 \\
\hline Other & $0.010(-0.029,0.049)$ & 0.599 & $0.017(-0.027,0.062)$ & 0.446 \\
\hline Hispanic/Latino & $0.005(-0.037,0.047)$ & 0.803 & $0.036(-0.013,0.085)$ & 0.149 \\
\hline \multicolumn{5}{|l|}{ Marital status } \\
\hline Married/cohabitate & $0.006(-0.011,0.022)$ & 0.500 & Ref & Ref \\
\hline Separated/divorced & $-0.005(-0.025,0.016)$ & 0.664 & $0.009(-0.014,0.031)$ & 0.446 \\
\hline Widowed & $0.001(-0.023,0.025)$ & 0.922 & $-0.013(-0.039,0.013)$ & 0.338 \\
\hline Never married & $-0.009(-0.035,0.018)$ & 0.515 & $-0.004(-0.033,0.025)$ & 0.784 \\
\hline \multicolumn{5}{|l|}{ Insurance type } \\
\hline Private & $0.008(-0.008,0.024)$ & 0.347 & Ref & Ref \\
\hline Medicaid & $-0.046(-0.075,-0.018)$ & 0.002 & $-0.026(-0.058,0.007)$ & 0.121 \\
\hline Medicare & $0.012(-0.004,0.028)$ & 0.138 & $-0.002(-0.023,0.018)$ & 0.844 \\
\hline Self-pay & $-0.027(-0.062,0.008)$ & 0.135 & $-0.029(-0.073,0.015)$ & 0.202 \\
\hline Years of education & $0.003(0.0003,0.005)$ & 0.028 & $0.0001(-0.003,0.003)$ & 0.949 \\
\hline Presence of PCP prior to admission & $0.007(-0.022,0.037)$ & 0.630 & $0.002(-0.032,0.036)$ & 0.888 \\
\hline Site & $-0.050(-0.065,-0.034)$ & $<0.0001$ & $-0.038(-0.056,-0.021)$ & $<0.0001$ \\
\hline №. of preadmission medications & $-0.0003(-0.002,0.001)$ & 0.684 & $-0.0001(-0.002,0.002)$ & 0.918 \\
\hline Medication understanding score per point & $0.007(-0.009,0.023)$ & 0.390 & $0.006(-0.011,0.023)$ & 0.513 \\
\hline Health literacy (s-TOFHLA) score per 10 points & $0.0006(-0.008,0.01)$ & 0.897 & $0.003(-0.008,0.01)$ & 0.644 \\
\hline Baseline adherence per point & $0.023(0.016,0.031)$ & $<0.0001$ & $0.017(0.009,0.024)$ & $<0.0001$ \\
\hline Cognitive function & $0.004(-0.022,0.031)$ & 0.757 & $0.008(-0.019,0.036)$ & 0.549 \\
\hline
\end{tabular}

NOTE: For crude estimates, value is category vs absence of parameter in univariable testing. For adjusted estimates of categorical variables, value is each category compared to referent category. Beta-coefficient represents absolute change in adherence (eg, 0.010 for age means a $1 \%$ absolute increase in adherence for every $10 \mathrm{yr}$ increase in patient age). Abbreviations: PCP, primary care physician; Ref, referent; s-TOFHLA, short form of the Test of Functional Health Literacy in Adults.

\begin{tabular}{lll}
\hline \multicolumn{2}{l}{ TABLE 3. Significant Results in Adjusted Analyses } \\
With Multiple Imputation & \\
\hline \multicolumn{3}{l}{ Parameter Estimate (Beta) } \\
Predictor & With $95 \%$ Confidence Intervals & $P$ Value \\
\hline $\begin{array}{l}\text { Age per } 10 \mathrm{yr} \\
\text { Insurance type }\end{array}$ & $0.010(0.004,0.020)$ & 0.004 \\
Private & Ref & Ref \\
Medicaid & $-0.045(-0.076,-0.014)$ & 0.005 \\
Medicare & $-0.010(-0.030,0.010)$ & 0.333 \\
Self-pay & $-0.013(-0.050,0.025)$ & 0.512 \\
Site & $-0.036(-0.053,-0.019)$ & $<0.0001$ \\
Baseline adherence per point & $0.016(0.008,0.024)$ & $<0.0001$ \\
\hline $\begin{array}{l}\text { NOTE: Total observations, } 646 ; 67 \text { with missing values. All variables adjusted for gender, race, cognitive } \\
\text { function, number of preadmission medications, marital status, health literacy score, medication understand- } \\
\text { ing score, presence of primary care physician (PCP), years of school, Hispanic/Latino ethnicity. } \\
\text { Abbreviations: Ref, referent. }\end{array}$ \\
\hline
\end{tabular}

compared with private insurance $(95 \% \mathrm{CI}-7.6 \%$ to $-1.4 \%$ ). Study site (specifically, Brigham and Women's Hospital) was also a significant predictor of greater postdischarge medication adherence. Years of education was a significant predictor of adherence in unadjusted analyses, but was not an independent predictor when adjusted for other factors. When baseline adherence was removed from the multiple imputation model, there were no changes in which factors were significant predictors of adherence.

\section{DISCUSSION}

In this study, we found that low baseline adherence, younger age, Medicaid insurance, and study site were sig- nificant predictors of lower 30-day medication adherence. Of particular interest is our finding regarding baseline adherence, a simple measure to obtain on hospitalized patients. It is notable that in our study, education was not an independent significant predictor of postdischarge adherence, even when baseline adherence was removed from the model. The same is true for medication understanding, cognitive function, and health literacy.

Older patients appeared more adherent with medications in the month after hospital discharge, perhaps reflecting increased interaction with the healthcare system (appointments, number of physician interactions), a greater belief in the importance of chronic medication management, or a higher level of experience with managing medications. A similar relationship between age and adherence has been shown in outpatient studies of patients with hypertension, diabetes, and other chronic diseases. ${ }^{24-27}$

Medicaid patients may be less likely to remain adherent because of the plan's limited coverage of medications relative to patients' ability to pay. For example, Medicaid in Tennessee covers the first 5 generic medications at no cost to the patient but has co-payments for additional medications and for brand name drugs. Medicaid in Massachusetts has co-payments of $\$ 1$ to $\$ 3$ for each medication. Alternatively, Medicaid insurance may be a marker for other patient characteristics associated with low adherence for which we were not fully able to adjust. 
Site differences were also notable in this study; these differences could have been due to differences in insurance coverage in Tennessee versus Massachusetts (which has near-universal coverage), differences in types of insurance (eg, fewer patients at Brigham and Women's Hospital had Medicaid than at Vanderbilt), cultural and geographic differences between the 2 locations, or other differences in transitional care between the 2 sites.

This study corroborates previous literature on medication adherence (specifically unintentional nonadherence) in the outpatient setting, ${ }^{4,8-11}$ for example, on the association of younger age with low adherence in certain populations. On the other hand, it may contrast with previous literature which has sometimes shown a relationship between patient education or health literacy and medication adherence. ${ }^{14,15,28-35}$ However, previous studies have not focused on the transition from inpatient to outpatient settings. Perhaps intensive medication education in the hospital, even under usual care, mitigates the effects of these factors on postdischarge adherence. Finally, baseline adherence seems to correlate with postdischarge adherence, a finding which makes intuitive sense and has been previously reported for specific medications. ${ }^{36}$

There are several limitations to this study. Although large, the study was performed at only 2 clinical sites where most patients were white and fairly well-educated, perhaps because patients admitted to a tertiary care center with ACS or ADHF are more affluent than general medical inpatients as a whole; this may limit generalizability. Postdischarge medication adherence might have been higher than in other patient populations given the nature of the population, possible lossto-follow-up bias, and the fact that half of the subjects received an intervention designed to improve medication management after discharge; such low rates of nonadherence in our study may have reduced our ability to detect important predictors in our models. In addition, the period of follow-up was 30 days, thus limiting our findings to short-term postdischarge medication adherence. Postdischarge medication adherence was based on patient self-report, which not only assumed that the patient was still managing his/her own medications after discharge, but may also be susceptible to both recall and social acceptability bias, which might overestimate our adherence scores, again limiting our ability to detect important predictors of nonadherence. However, other studies have shown a good correlation between self-reported medication adherence and other more objective measures, ${ }^{37,38}$ and recall was only for 7 days, a measure used previously in the literature ${ }^{39,40}$ and one designed to reduce recall bias. Systematic underreporting in certain patient populations is less likely but possible.

In the future, research should focus on targeting patients who have low baseline adherence to evaluate the effects of various interventions on postdischarge medication outcomes. Repeating the study in a population with a high prevalence of low health literacy might be illuminating, given that previous studies have shown that patients with low health literacy have less ability to identify their medications and have less refill adherence. ${ }^{29,30}$

In conclusion, in patients hospitalized with cardiovascular disease, predictors of lower postdischarge adherence include younger age, Medicaid insurance, and low baseline adherence. It may be prudent to assess baseline adherence and insurance type in hospitalized patients in order to identify those who may benefit from additional assistance to improve medication adherence and medication safety during transitions in care.

\section{Acknowledgements}

Meeting Presentations: SGIM New England Regional Meeting, oral presentation, Boston, MA, March 4, 2011; and SGIM National Meeting, poster presentation, Phoenix, AZ, May 6, 2011. Dr Schnipper had full access to all of the data in the study and takes responsibility for the integrity of the data and the accuracy of the data analysis.

Disclosures: Financial support was provided by R01 HL089755 (NHLBI, Kripalani), K23 HL077597 (NHLBI, Kripalani), K08 HL072806 (NHLBI, Schnipper), T32HP10251-02 (Cohen), and by the Division of General Medicine, Massachusetts General Hospital and the Harvard Medical School Fellowship in General Medicine and Primary Care (Cohen). Dr Kripalani is a consultant to and holds equity in PictureRx, LLC, which makes patient education tools to improve medication management. PictureRx did not provide materials or funding for this study. All other authors disclose no relevant or financial conflicts of interest.

\section{References}

1. Osterberg L, Blaschke T. Adherence to medication. N Engl J Med. 2005;353(5):487-497.

2. Coleman EA, Smith JD, Raha D, Min SJ. Posthospital medication discrepancies: prevalence and contributing factors. Arch Intern Med. 2005;165(16):1842-1847.

3. Cua YM, Kripalani S. Medication use in the transition from hospital to home. Ann Acad Med Singapore. 2008;37(2):136-141.

4. Moore C, Wisnivesky J, Williams S, McGinn T. Medical errors related to discontinuity of care from an inpatient to an outpatient setting. J Gen Intern Med. 2003;18(8):646-651.

5. Forster AJ, Murff HJ, Peterson JF, Gandhi TK, Bates DW. The incidence and severity of adverse events affecting patients after discharge from the hospital. Ann Intern Med. 2003;138(3):161-167.

6. Forster AJ, Murff HJ, Peterson JF, Gandhi TK, Bates DW. Adverse drug events occurring following hospital discharge. J Gen Intern Med. 2005;20(4):317-323.

7. Schnipper JL, Kirwin JL, Cotugno MC, et al. Role of pharmacist counseling in preventing adverse drug events after hospitalization. Arch Intern Med. 2006;166(5):565-571.

8. Vira T, Colquhoun M, Etchells E. Reconcilable differences: correcting medication errors at hospital admission and discharge. Qual Saf Health Care. 2006;15(2):122-126.

9. Hassan M, Lage MJ. Risk of rehospitalization among bipolar disorder patients who are nonadherent to antipsychotic therapy after hospital discharge. Am J Health Syst Pharm. 2009;66(4):358-365.

10. Mansur N, Weiss A, Hoffman A, Gruenewald T, Beloosesky Y. Continuity and adherence to long-term drug treatment by geriatric patients after hospital discharge: a prospective cohort study. Drugs Aging. 2008;25(10):861-870.

11. Kripalani S, Henderson LE, Jacobson TA, Vaccarino V. Medication use among inner-city patients after hospital discharge: patientreported barriers and solutions. Mayo Clin Proc. 2008;83(5): 529-535.

12. Lindquist LA, Go L, Fleisher J, Jain N, Friesema E, Baker DW. Relationship of health literacy to intentional and unintentional non-adherence of hospital discharge medications. J Gen Intern Med. 2012; 27(2):173-178.

13. Office of Disease Prevention and Health Promotion, US Department of Health and Human Services. Healthy People 2010. Available at: http://www.healthypeople.gov/Document/pdf/uih/2010uih.pdf. Accessed February 15, 2012. 
14. Davis TC, Wolf MS, Bass PF III, et al. Literacy and misunderstanding prescription drug labels. Ann Intern Med. 2006;145(12):887-894.

15. Kripalani S, Henderson LE, Chiu EY, Robertson R, Kolm P, Jacobson TA. Predictors of medication self-management skill in a low-literacy population. J Gen Intern Med. 2006;21(8):852-856.

16. Schnipper JL, Roumie CL, Cawthorn C, et al; for the PILL-CVD Study Group. Rationale and design of the Pharmacist Intervention for Low Literacy in Cardiovascular Disease (PILL-CVD) study. Circ Cardiovasc Qual Outcomes. 2010;3(2):212-219.

17. Borson S, Scanlan JM, Watanabe J, Tu SP, Lessig M. Simplifying detection of cognitive impairment: comparison of the Mini-Cog and Mini-Mental State Examination in a multiethnic sample. J Am Geriatr Soc. 2005;53(5):871-874.

18. Nurss JR. Short Test of Functional Health Literacy in Adults. Snow Camp, NC: Peppercorn Books and Press; 1998.

19. Morisky DE, Ang A, Krousel-Wood M, Ward HJ. Predictive validity of a medication adherence measure in an outpatient setting. J Clin Hypertens (Greenwich). 2008;10(5):348-354.

20. Marvanova M, Roumie CL, Eden SK, Cawthon C, Schnipper JL, Kripalani $S$. Health literacy and medication understanding among hospitalized adults. J Hosp Med. In press.

21. Marvanova M, Roumie CL, Eden SK, Cawthon C, Schnipper JL, Kripalani $S$. Health literacy and medication understanding among hospitalized adults. J Hosp Med. 2011;6(9):488-493.

22. Toobert DJ, Hampson SE, Glasgow RE. The summary of diabetes self-care activities measure: results from 7 studies and a revised scale. Diabetes Care. 2000;23(7):943-950.

23. Rubin DB. Multiple Imputation for Nonresponse in Surveys. New York, NY: John Wiley \& Sons; 1987.

24. Hinkin CH, Hardy DJ, Mason KI, et al. Medication adherence in HIV-infected adults: effect of patient age, cognitive status, and substance abuse. AIDS. 2004;18(suppl 1):S19-S25.

25. Wong MC, Jiang JY, Griffiths SM. Factors associated with antihypertensive drug compliance in 83,884 Chinese patients: a cohort study. J Epidemiol Community Health. 2010;64(10):895-901.

26. Wong MC, Kong AP, So WY, Jiang JY, Chan JC, Griffiths SM. Adherence to oral hypoglycemic agents in 26,782 Chinese patients: a cohort study. J Clin Pharmacol. 2011;51(10):1474-1482.

27. Gazmararian J, Jacobson KL, Pan Y, Schmotzer B, Kripalani S. Effect of a pharmacy-based health literacy intervention and patient characteristics on medication refill adherence in an urban health system. Ann Pharmacother. 2010;44(1):80-87.
28. Kalichman SC, Ramachandran B, Catz S. Adherence to combination antiretroviral therapies in HIV patients of low health literacy. $J$ Gen Intern Med. 1999;14(5):267-273.

29. Gazmararian JA, Kripalani S, Miller MJ, Echt KV, Ren J, Rask K. Factors associated with medication refill adherence in cardiovascularrelated diseases: a focus on health literacy. J Gen Intern Med. 2006; 21(12):1215-1221.

30. Persell SD, Osborn CY, Richard R, Skripkauskas S, Wolf MS. Limited health literacy is a barrier to medication reconciliation in ambulatory care. J Gen Intern Med. 2007;22(11):1523-1526.

31. Chew LD, Bradley KA, Flum DR, Cornia PB, Koepsell TD. The impact of low health literacy on surgical practice. Am J Surg. 2004; $188(3): 250-253$

32. Gatti ME, Jacobson KL, Gazmararian JA, Schmotzer B, Kripalani S. Relationships between beliefs about medications and adherence. Am J Health Syst Pharm. 2009;66(7):657-664.

33. Fang MC, Machtinger EL, Wang F, Schillinger D. Health literacy and anticoagulation-related outcomes among patients taking warfarin. J Gen Intern Med. 2006;21(8):841-846.

34. Paasche-Orlow MK, Cheng DM, Palepu A, Meli S, Faber V, Samet $\mathrm{JH}$. Health literacy, antiretroviral adherence, and HIV-RNA suppression: a longitudinal perspective. J Gen Intern Med. 2006;21(8): 835-840.

35. Platt $\mathrm{AB}$, Localio $\mathrm{AR}$, Brensinger $\mathrm{CM}$, et al. Risk factors for nonadherence to warfarin: results from the IN-RANGE study. Pharmacoepidemiol Drug Saf. 2008;17(9):853-860.

36. Muntner P, Mann DM, Woodward M, et al. Predictors of low clopidogrel adherence following percutaneous coronary intervention. Am J Cardiol. 2011;108(6):822-827.

37. Shi L, Liu J, Fonseca V, Walker P, Kalsekar A, Pawaskar M. Correlation between adherence rates measured by MEMS and self-reported questionnaires: a meta-analysis. Health Qual Life Outcomes. 2010;8: 99.

38. Shi L, Liu J, Koleva Y, Fonseca V, Kalsekar A, Pawaskar M. Concordance of adherence measurement using self-reported adherence questionnaires and medication monitoring devices. Pharmacoeconomics. 2010;28(12):1097-1107.

39. Grant RW, Devita NG, Singer DE, Meigs JB. Polypharmacy and medication adherence in patients with type 2 diabetes. Diabetes Care. 2003;26(5):1408-1412.

40. Grant RW, Devita NG, Singer DE, Meigs JB. Improving adherence and reducing medication discrepancies in patients with diabetes. Ann Pharmacother. 2003;37(7-8):962-969. 